\title{
Recent Experience in the Management of Neo- Vascular Glaucoma by Pan-Retinal Photocoagulation and Trabeculectomy
}

\author{
L. G. CLEARKIN \\ Liverpool
}

\begin{abstract}
Summary
Six patients were treated for neovascular glaucoma by pan-retinal photocoagulation followed by trabeculectomy. Control of intraocular pressure and relief of pain were achieved in all patients. Methods to improve the fundal view before laser are described and alternative methods of therapy are briefly discussed.
\end{abstract}

Neovascular glaucoma following central retinal vein occlusion is a well known clinical entity which was recognised soon after the introduction of the ophthalmoscope. ${ }^{1}$ It is seen following ischaemic central retinal vein occlusion, in which capilliary non-perfusion may be demonstrated on fluorescein angiogram. ${ }^{2,3}$ Ischaemic retina is thought to release a vasoformative factor ${ }^{4}$ which diffuses into the anterior segment stimulating angiogenesis on the surface of the iris and drainage angle. ${ }^{5}$ The iris new vessels have a fibrous tissue component which is not seen clinically but may be demonstrated histologically ${ }^{6}$ and by electron microscopy has been shown to consist of myofibroblasts, i.e. fibroblasts with smooth muscle differentiation. ${ }^{7}$ These cells have a contractile potential and cause ectropion uveae and cicatricial angle closure with subsequent elevation of intraocular pressure.

Retinal pan-photocoagulation is known to cause regression of retinal new-vessels in diabetes, ${ }^{8}$ and when used in branch retinal vein occlusion is noted to have a similar effect on iris new-vessels. ${ }^{9}$ Following this observation pan-retinal photocoagulation was undertaken in patients with iris neo-vascularisation $^{10}$ producing involution of the new-vessels. More recently pan-retinal photo- coagulation has been combined with subsequent drainage surgery successfully to treat neo-vascular glaucoma from a variety of causes. ${ }^{11.12}$

This report describes the treatment of six patients, who had established neo-vascular glaucoma following central retinal vein occlusion. Each patient underwent pan-retinal photocoagulation followed by trabeculectomy.

\section{Patients and Methods}

Six patients, who developed neovascular glaucoma following central retinal vein occlusion, were treated. Factors considered causal in the development of central retinal vein occlusion were present in three patients (Table I). Each patient had iris neovascularisation and markedly raised intraocular pressure at diagnosis. Treatment by laser photocoagulation was thought possible if the fundus could be visualised by indirect ophthalmoscopy.

When the diagnosis was first made, each patient was treated with atropine and steroid drops. This served not only to alleviate ocular discomfort, but also to maintain pupillary dilation until laser therapy was completed.

Laser therapy was performed as an outpatient procedure (except in the case of patient 5 , in whom the condition was bilateral, who was admitted to hospital). Treatment was given in two to four ses- 
Table I Summary of details of each patient

\begin{tabular}{|c|c|c|c|c|}
\hline Case no & Age & Sex & Diagnosis & Precipitating factor \\
\hline 1 & 52 & Male & R. CRVO & Open angle glaucoma \\
\hline 2 & 46 & Male & L. CRVO & Idiopathic \\
\hline 3 & 70 & Male & R. CRVO & Type II diabetes \\
\hline 4 & 67 & Female & L. CRVO & Hypertension \\
\hline 5 & 70 & Male & Bilateral CRVO & Idiopathic \\
\hline 6 & 80 & Female & L. CRVO & Idiopathic \\
\hline
\end{tabular}

sions over one to six weeks. Laser treatment was judged to have been adequate when the iris new vessels were seen to regress on follow-up examination. The vessels became reduced in calibre and number and appeared less active. ${ }^{9}$ As can be seen from Table II, between 3,000 and 7,000 burns were needed to achieve this response.

A trabeculectomy was then performed. No attempt was made to reduce intraocular pressure immediately prior to operation. Surgery was performed in the usual way!12 The conjunctiva was inscised anterior to the superior rectus muscle, and reflected over the cornea in order to facilitate dissection of a lamellar scleral flap. A rectangular block of tissue was then excised from the peripheral cornea. In a number of patients following removal of this block of tissue a fibrous membrane underlying the peripheral cornea was discovered and removed without difficulty by sharp dissection before a peripheral iridectomy was performed. The scleral flap and conjunctival flap were then sutured. Post-operatively treatment with atropine and steroid drops was continued until post-operative inflammation had settled.

As may be seen from Table II, three patients required Timoptol drops in addition to surgery to control their intraocular pressure.

Follow-up is for a minimum of six months in each patient and intraocular pressure and visual acuity measurements are given for that time. No substan- tial change in either measurement has occurred in any patient having a longer follow-up period.

\section{Results}

The results of treatment are summarised in Table II. Following control of intraocular pressure all patients became pain free. This usually occurred within ten days of trabeculectomy.

Visual acuity was maintained at the pretreatment level in four of the six patients, two patients suffered loss of actuity, patient 5 from $6 / 36$ to $3 / 60$ and patient 6 from hand movements to perception of light. This was particularly distressing in the case of patient 5 as this was his only seeing eye. No patient developed a measurable improvement in visual acuity.

Satisfactory control of intraocular pressure was achieved in all six patients. Patients 1,2 and 6 required the addition of timolol drops, to reduce intraocular pressure to a satisfactory level, the remaining three patients achieved control without additional medication.

Following treatment, with the exception of the reduction of vision in the two patients previously described, no other complication from treatment were seen.

Table II Summary of the pretreatment state of each patient's affected eye(s), the treatment given (each patient underwent trabeculectomy also), the result of treatment, and any additional treatment

\begin{tabular}{ccccccc}
\hline & $\begin{array}{c}\text { Presenting } \\
\text { VA }\end{array}$ & $\begin{array}{c}\text { Presenting } \\
\text { IOPmmHg } \\
\text { (affected eye) }\end{array}$ & Laser & $\begin{array}{c}\text { VA at } \\
\text { (affected eye) } \\
\text { follow-up }\end{array}$ & $\begin{array}{c}\text { IOP at } \\
\text { (2 months } \\
\text { follow-up }\end{array}$ & $\begin{array}{c}\text { Additional } \\
\text { medication }\end{array}$ \\
\hline \multirow{2}{*}{1} & 6/36 & 60 & 3046 & $6 / 36$ & 16 & Timolol $0.5 \%$ \\
2 & C.F. & 50 & 7046 & C.F. & 18 & Timolol $0.5 \%$ \\
3 & H.M. & 68 & 3833 & H.M. & 14 & Nil \\
4 & C.F. & 60 & 5716 & C.F. & 18 & Nil \\
5 & F. NPL & 70 & None & NPL & 50 & Atropine and steroid \\
& L. 6/36 & 56 & 3614 & $3 / 60$ & 14 & Nil \\
6 & H.M. & 50 & 4953 & P.L. & 22 & Timolol $0.5 \%$ \\
\hline
\end{tabular}

* This eye received symptomatic treatment with atropine and steroid drops only. 


\section{Discussion}

The aims of treatment in neovascular glaucoma ${ }^{11}$ are to preserve the eye, to render it pain free, to preserve vision and to avoid the complications of neovascular glaucoma (e.g. corneal abscess in bullous keratopathy). Four of the six patients have been successfully treated, the two patients who partially lost vision, can be said to have been treated with a degree of success.

It is clear that only a proportion of patients who present with neovascular glaucoma will be suitable for treatment in this way. The over-riding factor is clarity of the ocular media, sufficient to allow laser photocoagulation. There can be no general statement as to these criteria but often, these patients were judged treatable if at least a view of the disc and major vessels were obtained on indirect ophthalmoscopy.

Fundal view may be compromised by corneal oedema, hyphaema, posterior synaechiae cataract and vitreous haemorrhage. Of these only corneal oedema and posterior synaechiae can be influenced by non-surgical means. It is an advantage to maintain pupillary dilatation using atropine from the time the diagnosis is first made. Corneal oedema can be reduced by lowering intraocular pressure with systemic acetazolamide and local timolol drops. These should not be given on a long-term basis, but rather for a day or two before laser treatment is undertaken. Of more practical use is glycerin used topically to 'clear' corneal oedema, given as drops immediately before laser, and also as the funduslens solution, thus prolonging its action.

Use of the panfundoscope as the delivery lens for photocoagulation is of immense benefit, often treatment can be given with this lens when it would not be possible with a Goldman three mirror lens. Combining these manoeuvres can often improve fundal view to a level when treatment may be given, when otherwise it would not be possible. In performing panretinal photocoagulation, in general more burns were given at a higher power setting than would be given in panretinal photocoagulation for diabetic disc neovascularisation. Usually they were of $200 \mu$ spot size and the power settings increased until visible blanching was seen. If this failed then the spot size was reduced to $100 \mu$.

From the results of this study, a minimum of 3,000 high energy burns are needed. However, this figure cannot be taken as a rule and it is better to rely on visible regression of iris new vessels in judging the endpoint of laser treatment. When this point is reached a trabeculectomy may be performed.

In the past, a variety of medical treatments for neovascular glaucoma have been advocated but have proved disappointing. ${ }^{10,13}$ More recently Blach $^{14}$ has outlined an approach to the management of neovascular glaucoma in diabetic eye disease which is equally applicable to neovascular glaucoma from other causes. Laser pan-retinal photocoagulation is advocated in eyes with clear media, and retinal cryotherapy in those eyes with opaque media. Following reduction of the stimulus for new vessel growth by either of these means, then conventional drainage surgery may be performed in those eyes which show regression of iris new vessels. When this response is not found then insertion of a Molteno tube may be used. ${ }^{15}$ In those eyes which have lost perception of light, symptomatic treatment with atropine and steroid drops is recommended. Obviously this treatment has no effect on intraocular pressure and the complications of bullous keratopathy. It may be argued that aggressive treatment in order to control intraocular pressure is indicated not only to alleviate pain more effectively, but also to prevent the complications of bullous keratopathy such as rupture of bullae with subsequent infection and corneal abscess formation, which is a common complication requiring prolonged, often painful treatment and eventual enucleation. The same can be said for retro-bulbar alcohol injection, which although very effective at relieving pain, produces a compromised eye, which is often a cosmetic embarrassment because of the associated ophthalmoplegia. Enucleation should be regarded as an undesirable method of treatment, and only used when all else has failed.

The ultimate prognosis of neovascular glaucoma is well known. The proportion of patients who can initially be treated with laser pan-retinal photocoagulation is small, but 
may be increased by implementing the various manoeuvres described to improve the clarity of the media. Laser treatment is logical, effective and a technique familiar to ophthalmologists involved in the management of retinal disease. Trabeculectomy is also a familiar technique and combining the two can provide effective treatment for neovascular glaucoma.

\section{References}

${ }^{1}$ von Graefe A: Beiträge zur Pathologie und Therapie des Glaucoms. Abhängigkeit von der Netzhaut. Albrecht von Graefes Arch. Ophthalmol. 1869; 15 (3): 184-94.

${ }^{2}$ Laatikainen L, Kohner EM: Fluorescein angiography and its prognostic significance in central retinal vein occlusion. Br. J. Ophthalmol. 1968; 64: 411-16.

${ }^{3}$ Tasman W, Margaral LE, Augsberger JJ: Effects of argon laser photocoagulation on rubeosis iridis and angle neovascularisation. Ophthalmology 1980; 87: 400-2.

${ }^{4}$ Wise GN: Retinal neovascularisation. Trans. Am. Ophthalmol. Soc. 1956; 54: 729-826.

${ }^{5}$ Ashton N: Retinal vascularisation in health and disease. Am. J. Ophthalmol. 1957; 44: 7-17.

${ }^{6}$ Kurz O: Zur Rubeosis iridis diabetica. Arch. Augenheilkd. 1937; 110: 284-92.
${ }^{7}$ Aiello LM, Briones JC: Ruby laser photocoagulation of proliferating diabetic retinopathy: fifth year of follow-up. Int. Ophthalmol. Clin. 1976; 16: $15-23$.

${ }^{8}$ Krill AE, Archer D, Newell FW: Photocoagulation in complications secondary to branch retinal vein occlusion. Arch. Ophthalmol. 1971; 85: 48-60.

${ }^{9}$ Little HL, Rosenthal AR, Dellaporta A, Jackson DR: The effect of pan-retinal photocoagulation on rubeosis iridis. Am. J. Ophthalmol. 1976; 91: 804-9.

10 Wand M: Neovascular glaucoma. In: Ritch $\mathrm{R}$ and Sheilds MB (eds) The Secondary Glaucomas C. V. Mosby 1982.

${ }^{11}$ Flanagan DW, Blach RK: Place of panretinal photocoagulation and trabeculectomy in the management of neovascular glaucoma. $\mathrm{Br}$. J. Ophthalmol. 1983; 67: 526-8.

12 Cairns JE: Trabeculetcomy. Preliminary report of a new method. Am. J. Ophthalmol. 1968; 66: 673-9.

${ }^{13}$ Grant WM: Management of neovascular glaucoma In: Symposium on Ocular Therapy, vol 7 Leopold IH (ed), C. V. Mosby, St Louis 1978.

${ }^{14}$ Blach RK: the management of diabetic retinopathy. In: Recent Advances in Ophthalmology no 7 (Davidson SI, Fraunfelder FT eds) Churchill Livingstone, London 1985

${ }^{15}$ Molteno MBC, Von Rooyen MMB, Bartholomew RS: Implants for draining neovascular glaucoma. Br. J. Ophthalmol. 1977; 61: 120-5. 